\title{
Stay at Home Parent
}

National Cancer Institute

\section{Source}

National Cancer Institute. Stay at Home Parent. NCI Thesaurus. Code C148253.

A homemaker whose work includes caring for children. 